\title{
Increasing Maternal Body Mass Index Is Associated With Fetal Defects
}

\author{
Marion T. Van Mackelenbergh ${ }^{1 *}$, Melanie Marotte ${ }^{1}$, Ibrahim Alkatout $^{1}$, Constantin S. von Kaisenberg ${ }^{2}$, \\ Christel Eckmann-Scholz ${ }^{1}$
}

\begin{abstract}
Objectives: To test the hypothesis, that increasing maternal weight is directly related to the incidence of fetal anomalies, to rank anomalies according to their frequency and to establish detection rates for the various anomalies with increasing body mass index (BMI).

Materials and Methods: Retrospective single center matched case control study, analysis of the association between maternal BMI and the frequency and type of fetal anomalies and establishment of the sensitivity of ultrasound scans in relation to the maternal BMI.

Results: There were 182 fetal anomalies which were matched with healthy controls. The main findings of the study are, that maternal BMI was significantly increased in pregnancies with fetal anomalies, in particular in overweighed women the risk was 1.6 fold increased for a fetal anomaly, in obesity it was even 2.1 fold. The most common anomaly were cardiac defects, urogenital defects were second. The chance for a neural tube defects was 10.7 times increased. Although vision was impaired, $94.7 \%$ of the cases were diagnosed correctly by prenatal ultrasound, the detection rate deteriorating with decreasing sensitivity in obese women.

Conclusion: There is an increase of fetal anomalies with increasing maternal weight whereas the detection rate for fetal defects declines.

Keywords: Fetal development, Body mass index, Ultrasonography
\end{abstract}

\section{Introduction}

The incidence of obesity is constantly rising and is developing into a relevant economic and public health concern. According to the World Health Organization (WHO) 1.4 billion people in the world suffered from obesity in 2008 . Of these 0.3 billion were women including those of childbearing age.

In pregnancy, obesity increases the risks both for the mother and fetus. Maternal risks are thromboembolism, gestational diabetes, preeclampsia, hypertension and urogenital infections (1-3). Moreover, an increased maternal body mass index (BMI) has been shown to be a risk factor for spontaneous abortion and intrauterine fetal death $(2,4)$. A recent study demonstrated that obese women who suffered two or more abortions tended to have a higher incidence of euploid abortions (5). Regarding delivery, a higher rate of cesarean sections has been described in obese women with an increase in surgical and postoperative complications $(3,6)$. Children of women with a high BMI are more likely to be delivered preterm with a subsequent need for neonatal intensive care treatment $(7,8)$. In addition, maternal obesity is linked to high infant birth weight, subsequent complications during delivery and an increased incidence of children suffering from a metabolic syndrome in their later lives $(9,10)$. However, the occur- rence of congenital fetal anomalies has also been associated with obesity in pregnant women. A meta-analysis of 12 studies could confirm an association between maternal obesity and an increased risk of neural tube defects (11), whereas another meta-analysis of 18 studies showed an association between the incidence of fetal hydrocephaly, cardiovascular anomalies, cleft palate, anorectal atresia and limb reduction anomalies (12). Interestingly, the risk of gastroschisis was significantly reduced in obese mothers. On the other hand, congenital anomalies are a major risk factor for perinatal and infant death (13).

Prenatal ultrasound scans are utilized to detect congenital malformations in pregnancy. The effect of maternal overweight and obesity on the sensitivity of ultrasound diagnostics has been reported previously. Aagaard-Tillery et al described that maternal obesity significantly decreased the likelihood of sonographic detection of common anomalies in 8555 pregnancies with available BMI (14). This would lead to the assumption that obese women not only tend to have a higher risk of having children with congenital anomalies but also suffer from lower detection rates which has implications on antenatal counseling in this group (15).

The aim of this retrospective case-control study was to investigate the association between maternal BMI and con-

Received 19 January 2016, Accepted 20 May 2016, Available online 3 July 2016

${ }^{1}$ University Hospital of Schleswig-Holstein, Campus Kiel, Department of Obstetrics and Gynecology, Kiel, Germany. 2Hannover University Medical School, Department of Obstetrics and Gynecology, Hannover, Germany.

*Corresponding Author: Marion T. van Mackelenbergh, University Hospital of Schleswig-Holstein, Campus Kiel, Department of Obstetrics and

Gynecology, Arnold-Heller-Strasse 3, 24105 Kiel, Germany. Tel: +494315972100; Email: marion.vanmackelenbergh@uksh.de 
genital malformations, to establish the distribution of fetal defects and to assess detection rates as maternal weight increases in obese women in a single center.

\section{Materials and Methods}

This study was conducted as a retrospective case-control study in which every case of a congenital anomaly was matched with a healthy control according to age, BMI, maternal diabetes, number of previous deliveries, nicotine consume and number of fetuses.

\section{Patient Population}

The database of prenatal ultrasound examinations performed by certified sonographers using either an ATL HDI 8000 sono CT (Philips, NL), a GE Voluson E8 (GE Healthcare, GB) or a Philips iu22 (Philips, NL) between 1 January 2000 and 17 December 2011 in the department of Obstetrics and Gynecology of the University Hospital Schleswig-Holstein, Campus Kiel was screened for congenital anomalies detected. The software utilized was ViewPoint-Pia Fetal database software (GE Healthcare, Wesling, Germany). A database search identified 508 cases of anomalies. Patients were included if an anomaly was detected antenatally, available information on pregnancy outcome and confirmation of congenital malformation existed. Exclusion criteria were healthy born infants, preexisting diabetes, chromosomal anomalies, genetic defects and anomalies caused by maternal infections. This lead to the exclusion of 326 cases leaving 182 cases for further analysis. The cases were matched with control cases from the same hospital according to their maternal age at first presentation, for antenatal ultrasound, number of previous deliveries and nicotine consumption.

\section{Statistical Analyses}

Statistical analysis was performed using Microsoft Excel 2013 (Microsoft, WA) and SPSS Statistics 22 (IBM, NY). Statistical tests used were the Wilcoxon matched pairs test, chi square test as well as the Kolmogorov-Smirnov test and $P$ values $<0.05$ were declared significant.

\section{Results}

\section{Patient Characteristics}

The patient characteristics are displayed in Table 1. Among the cases $96.2 \%$ were single pregnancies, 6 twins and one triplet. Controls were matched accordingly. In both groups $17.6 \%$ of pregnant patients smoked and all confirmed alcohol abstinence. Among the groups 53.9\% were primigravida and $3 \%$ developed gestational diabetes. The majority of patients were between 30 and 34 years of age (33\%) followed by the age group of 35 years and older (19.8\%). Regarding maternal BMI, differences could be observed between the case and control group (Figure 1). The mean BMI among the cases was $25.3 \mathrm{~kg} / \mathrm{m}^{2}$ compared to $23.7 \mathrm{~kg} / \mathrm{m}^{2}$ in the control group. Especially the number of women with a BMI equal or above $30 \mathrm{~kg} / \mathrm{m}^{2}$ was higher in the case group (18.7\%) than in the control group (10.4\%).
Table 1. Patient Characteristics

\begin{tabular}{|c|c|c|}
\hline & $\begin{array}{l}\text { Cases: Number (\%) } \\
\mathrm{n}=182\end{array}$ & $\begin{array}{l}\text { Controls: Number (\%) } \\
n=182\end{array}$ \\
\hline \multicolumn{3}{|l|}{ No. of fetus } \\
\hline 1 & $175(96.2 \%)$ & 177 (97.3\%) \\
\hline 2 & $6(3.3 \%)$ & $5(2.7 \%)$ \\
\hline 3 & $1(0.5 \%)$ & 0 \\
\hline \multicolumn{3}{|l|}{ Nicotine consumption } \\
\hline Yes & $32(17.6 \%)$ & $32(17.6 \%)$ \\
\hline No & $150(82.4 \%)$ & $150(82.4 \%)$ \\
\hline \multicolumn{3}{|l|}{ No. of previous birth } \\
\hline 0 & $98(53.9 \%)$ & $98(53.9 \%)$ \\
\hline 1 & $54(29.7 \%)$ & $55(30.2 \%)$ \\
\hline 2 & $19(10.4 \%)$ & $19(10.4 \%)$ \\
\hline 3 or more & $11(6.0 \%)$ & $10(5.5 \%)$ \\
\hline \multicolumn{3}{|l|}{ Maternal diabetes } \\
\hline Absence & $165(97.1 \%)$ & $125(96.9 \%)$ \\
\hline Gestational diabetes & $5(2.9 \%)$ & $4(3.1 \%)$ \\
\hline Unknown & 12 & 53 \\
\hline \multicolumn{3}{|l|}{ Maternal BMI in kg/m² } \\
\hline$<18.5$ & $7(3.8 \%)$ & $5(2.7 \%)$ \\
\hline $18.5-24.9$ & $103(56.6 \%)$ & $122(67 \%)$ \\
\hline 25-29.9 & 38 (20.9\%) & $36(19.8 \%)$ \\
\hline$\geq 30$ & $34(18.7 \%)$ & $19(10.4 \%)$ \\
\hline \multicolumn{3}{|l|}{ Age } \\
\hline$<20$ & $7(3.8 \%)$ & $7(3.8 \%)$ \\
\hline $20-24$ & $27(14.8 \%)$ & $27(14.8 \%)$ \\
\hline $25-29$ & $52(28.6 \%)$ & $52(28.6 \%)$ \\
\hline $30-34$ & $60(33.0 \%)$ & $60(33 \%)$ \\
\hline $35-39$ & $30(16.5 \%)$ & $30(16.5 \%)$ \\
\hline$\geq 40$ & $6(3.3 \%)$ & $6(3.3 \%)$ \\
\hline
\end{tabular}

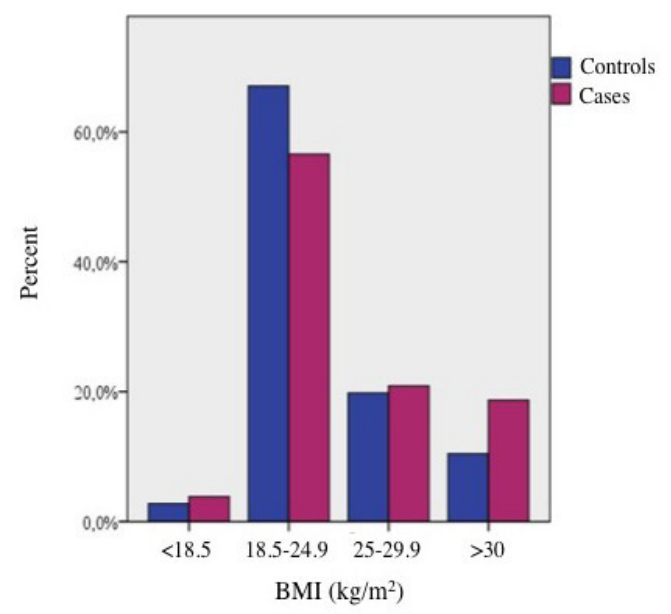

Figure 1. Maternal BMI in the Case and Control Group.

Fetal Anomalies

The majority of cases were diagnosed with cardiovascular anomalies (37.9\%) followed by urogenital malformations (18.7\%) (Figure 2). Central nervous system and multiple malformations were presented at $12.8 \%$ and $14.8 \%$, respectively.

Among the 182 cases were 3 newborns with cleft palate. Six respiratory tract malformations were diagnosed, 5 of them before 30 weeks of gestation by ultrasound. There 


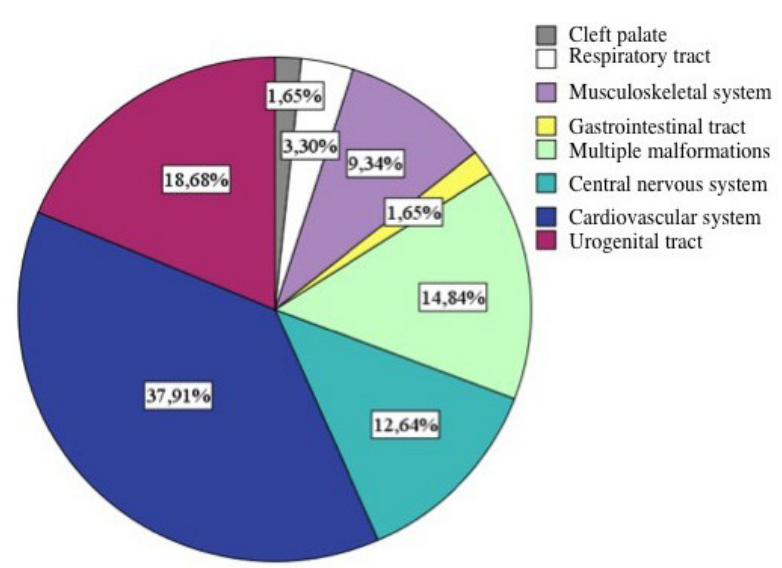

Figure 2. Subgroups of Fetal Malformations.

were 7 cases of musculoskeletal malformations, all of them were diagnosed prior to 30 weeks of gestation. In 8 cases a gastroschisis was diagnosed and 2 fetuses presented with omphaloceles, ending in one intrauterine demise. Three cases of gastrointestinal tract malformations were diagnosed correctly prenatally. Twenty-seven fetuses in the case group had multiple malformations. Nineteen of these were diagnosed before 30 weeks of gestation of which one diagnosis was incorrect. One fetus suffered from intrauterine death, 3 died postnatally and 3 pregnancies were terminated according to legal right. Of 23 cases with central nervous system malformations 13 suffered from neural tube defects (57\%) and 6 from hydrocephalus (26\%). 94.7\% were diagnosed correctly before 30 weeks of gestation and $43.5 \%$ of pregnancies were terminated. Twenty-eight percent of the cardiovascular anomalies were conotruncal and the majority of these were left ventricular obstructions. Sensitivity of diagnosis was $94.7 \%$ and $88.4 \%$ resulted in live births. Sensitivity of ultrasound diagnosis of urogenital tract malformations was $90.5 \%$ in this cohort. The majority of defects included obstructions of the urinary tract (65\%). Four (12\%) were diagnosed with multicystic renal dysplasia.

Overall, $94.7 \%$ of cases were diagnosed correctly prior to 30 weeks of gestation. Sensitivity among underweighted women (BMI $<18.5 \mathrm{~kg} / \mathrm{m}^{2}$ ) was $100 \%$ compared to $95.5 \%$ in the normal weight group (BMI $18.5-24.9 \mathrm{~kg} / \mathrm{m}^{2}$ ) and this dropped to $93.6 \%$ in the overweighted (BMI 25-29.9 $\left.\mathrm{kg} / \mathrm{m}^{2}\right)$ and obese cohort $\left(\mathrm{BMI}>30 \mathrm{~kg} / \mathrm{m}^{2}\right) .80 .8 \%$ resulted in live birth and terminations of pregnancy were performed in 9.3\%. 2.2\% suffered from intrauterine death and $7.7 \%$ of newborns died postnatally.

Association Between Maternal BMI and Fetal Anomalies The BMI in the case and control group were significantly different with the higher BMI levels in the case group $(P=0.022)$. A significant association between a maternal BMI $>25 \mathrm{~kg} / \mathrm{m}^{2}$ and fetal anomalies could be detected $(P=0.049)$. This association was even stronger in the group of obese women with a BMI above $30 \mathrm{~kg} / \mathrm{m}^{2}(P=0.016)$. Regarding the different organ systems there was an association of maternal obesity with respiratory tract anomalies $(P=0.004)$ as well as gastrointestinal tract malformations $(P=0.01)$ and multiple malformations $(P=0.015)$ (Table $2)$. An association between maternal overweight with central nervous system anomalies could be detected as well $(\mathrm{p}=0.017)$. Especially neural tube defects occurred in the overweighed and obese cohorts $(P=0.001)$.

Obese women had a twice as high risk of having a child with anomalies compared to normal weight women (OR 2.1, CI 1.1-3.9) (Table 3). In detail, the risks of respiratory tract anomalies (OR 9.6, CI 1.5-61.5), gastrointesti-

Table 2. Fetal Malformations in BMI Subgroups

\begin{tabular}{|c|c|c|c|c|}
\hline Fetal Malformations & $\begin{array}{l}\text { Underweighed }(\mathrm{BM}<18.5) \\
P \text { value }\end{array}$ & $\begin{array}{l}\text { Overweighed (BMI 25-29.9) } \\
P \text { value }\end{array}$ & $\begin{array}{l}\text { Obesity }(\mathrm{BMI} \geq 30 \text { ) } \\
P \text { value }\end{array}$ & $\begin{array}{l}\mathrm{BMI} \geq 25 \\
P \text { value }\end{array}$ \\
\hline Total & 0.395 & 0.405 & 0.016 & 0,049 \\
\hline Cleft palate & - & - & - & - \\
\hline Respiratory tract & - & 0.667 & 0.004 & 0,067 \\
\hline Musculoskeletal system & 0.421 & 0.981 & 0.344 & 0,596 \\
\hline Gastroschisis & 0.142 & - & 0.264 & 0,888 \\
\hline Others & - & 0.338 & 0.823 & 0,400 \\
\hline Gastrointestinal tract & - & - & 0.01 & 0,189 \\
\hline Multiple & - & 0.487 & 0.015 & 0,317 \\
\hline CNS & 0.039 & 0.137 & 0.008 & 0,017 \\
\hline Neural tube defects & - & 0.011 & 0.000 & 0,001 \\
\hline Hydrozephalus & 0.047 & 0.917 & 0.510 & 0,671 \\
\hline others & 0.047 & - & - & - \\
\hline Cardiovascular system & 0.2 & 0.424 & 0.622 & 0,390 \\
\hline Conotruncal & 0.421 & 0.359 & 0.344 & 0,248 \\
\hline Left venrticular obstruction & - & 0.339 & 0.676 & 0,348 \\
\hline Cardiac valve-/septum anomalies & 0.000 & 0.722 & - & 0,888 \\
\hline Others & - & - & 0.951 & 0,344 \\
\hline Urogenital tract & - & 0.396 & 0.736 & 0,413 \\
\hline Multicystic renal dysplasia & - & 0.667 & 0.325 & 0,420 \\
\hline Obstructive defects & - & 0.730 & 0.639 & 0,615 \\
\hline Others & - & 0.338 & - & 0,702 \\
\hline
\end{tabular}


Table 3. Odds Ratios for Fetal Malformations in the BMI Subgroups ${ }^{\text {a }}$

\begin{tabular}{|c|c|c|c|c|c|c|c|c|c|c|}
\hline \multirow[t]{2}{*}{ Fetal malformations } & \multirow[t]{2}{*}{ Total } & \multirow{2}{*}{$\begin{array}{c}\text { Normal Weight } \\
\text { (BMI 18.5-24.9 } \\
\left.\mathrm{kg} / \mathrm{m}^{2}\right) \\
\mathrm{n}\end{array}$} & \multicolumn{2}{|c|}{$\begin{array}{c}\text { Underweight } \\
\left(\mathrm{BM}<18.5 \mathrm{~kg} / \mathrm{m}^{2}\right)\end{array}$} & \multicolumn{2}{|c|}{$\begin{array}{c}\text { Overweight } \\
\left(\mathrm{BMI} 25-29.9 \mathrm{~kg} / \mathrm{m}^{2}\right)\end{array}$} & \multicolumn{2}{|c|}{$\begin{array}{c}\text { Obesity } \\
\left(\mathrm{BMI} \geq 30 \mathrm{~kg} / \mathrm{m}^{2}\right)\end{array}$} & \multicolumn{2}{|c|}{$\mathrm{BMI} \geq 25 \mathrm{~kg} / \mathrm{m}^{2}$} \\
\hline & & & $\mathrm{n}$ & OR (95 \% Cl) & $\mathbf{n}$ & OR (95 \% Cl) & $\mathbf{n}$ & OR (95 \% Cl) & $\mathbf{n}$ & OR (95 \% Cl) \\
\hline None (controls) & 182 & 122 & 5 & & 36 & & 19 & & 55 & \\
\hline Malformations in total & 182 & 103 & 7 & $1.7(0.5-5.4)$ & 38 & $1.3(0.7-2.1)$ & 34 & $2.1(1.1-3.9)$ & 72 & $1.6(1-2.4)$ \\
\hline Cleft palate & 3 & 3 & 0 & - & 0 & - & 0 & - & 0 & - \\
\hline Respiratory tract & 6 & 2 & 0 & - & 1 & $1.7(0.1-19.2)$ & 3 & $9.6(1.5-61.5)$ & 4 & $4.4(0.8-24.9)$ \\
\hline Musculoskeletal system & 17 & 10 & 1 & $2.4(0.3-23)$ & 3 & $1(0.3-3.9)$ & 3 & $1.9(0.5-7.6)$ & 6 & $1.3(0.5-3.8)$ \\
\hline Gastroschisis & 8 & 5 & 1 & $4.9(0.5-49.9)$ & 0 & - & 2 & $2.6(0.5-14.2)$ & 2 & $0.9(0.2-4.7)$ \\
\hline Others & 9 & 5 & 0 & - & 3 & $2(0.5-8.9)$ & 1 & $1.3(0.1-11.6)$ & 4 & $1.8(0.5-6.9)$ \\
\hline Gastrointestinal tract & 3 & 1 & 0 & - & 0 & - & 2 & $12.8(1.1-148.6)$ & 2 & $4.4(0.4-50.0)$ \\
\hline Multiple & 27 & 16 & 0 & - & 3 & $0.6(0.2-2.3)$ & 8 & $3.2(1.2-8.5)$ & 11 & $1.5(0.7-3.5)$ \\
\hline CNS & 23 & 9 & 2 & $5.4(0.9-32.0)$ & 6 & $2.3(0.8-6.8)$ & 6 & $3.2(1.2-8.5)$ & 12 & $3(1.2-7.4)$ \\
\hline Neural tube defects & 13 & 3 & 0 & - & 5 & $5.6(1.3-24.8)$ & 5 & $10.7(2.4-48.5)$ & 10 & 7.4 (2.0-27.9) \\
\hline Hydrocephalus & 6 & 3 & 1 & $8.1(0.7-92.7)$ & 1 & $1.1(0.1-11.2)$ & 1 & $2.1(0.2-21.7)$ & 2 & $1.5(0.2-9.1)$ \\
\hline Others & 4 & 3 & 1 & $8.1(0.7-92.7)$ & 0 & - & 0 & - & 0 & - \\
\hline Cardiovascular system & 69 & 41 & 4 & $2.4(0.6-9.3)$ & 16 & $1.3(0.7-2.6)$ & 8 & $1.3(0.5-3.1)$ & 24 & $1.3(0.7-2.4)$ \\
\hline Conotruncal & 19 & 10 & 1 & $2.4(0.3-23.0)$ & 5 & $1.7(0.5-5.3)$ & 3 & $1.9(0.5-7.6)$ & 8 & $1.8(0.7-4.7)$ \\
\hline Left ventricular obstruction & 33 & 20 & 0 & - & 9 & $1.5(0.6-3.6)$ & 4 & $1.3(0.4-4.2)$ & 13 & $1.4(0.7-3.1)$ \\
\hline $\begin{array}{l}\text { Cardiac valve-/ Septum } \\
\text { anomalies }\end{array}$ & 10 & 5 & 3 & $14.6(2.7-79.2)$ & 2 & $1.4(0.3-7.3)$ & 0 & - & 2 & $0.9(0.2-4.7)$ \\
\hline Others & 7 & 6 & 0 & - & 0 & - & 1 & $1(0.1-9.4)$ & 1 & $0.4(0.0-3.1)$ \\
\hline Urogenital tract & 34 & 21 & 0 & - & 9 & $1.5(0.6-3.4)$ & 4 & $1.2(0.4-4)$ & 13 & $1.4(0.6-2.9)$ \\
\hline Multicystic Renal dysplasia & 4 & 2 & 0 & - & 1 & $1.7(0.1-19.2)$ & 1 & $3.2(0.3-37.2)$ & 2 & $2.2(0.3-16.2)$ \\
\hline Obstructive defects & 22 & 14 & 0 & - & 5 & $1.2(0.4-3.6)$ & 3 & $1.4(0.4-5.2)$ & 8 & $1.3(0.5-3.2)$ \\
\hline Others & 8 & 5 & 0 & - & 3 & $2.0(0.5-8.9)$ & 0 & - & 3 & $1.3(0.3-5.8)$ \\
\hline
\end{tabular}

${ }^{a}$ Odds ratios with $P$ values $<0.05$ are printed in bold.

nal tract anomalies (OR 12.8, CI 11.0-148.6), and neural tube defects (OR 10.7, CI 2.4-48.5) were especially high in obese women. On the other hand, overweighed women had a 6 fold increased risk of carrying a fetus with neural tube defects (OR 5.6, CI 1.3-24.8). In contrast, underweighted women had an increased risk of being diagnosed with a fetus with heart defects (OR 14.6, CI 2.7-79.2).

\section{Discussion}

This retrospective matched case control study could show an association between maternal BMI and fetal anomalies. In this cohort, the risk of carrying a fetus with anomalies was twice as high for obese women compared to women with a normal BMI. These results are similar to a prospective study performed in Ireland including 3565 patients, that demonstrated a 2.5 fold risk increase (16). A significant association between BMI and fetal malformations could not be determined in the group of overweighed women in their study as well as in the here presented data. In this study, it was possible for the first time to detect an association between fetal respiratory tract anomalies and maternal obesity although the number of cases was very small. This has to be confirmed in larger cohorts. Concerning musculoskeletal anomalies there was no significant association with maternal BMI which is conform with the data presented by Queisser-Luft et al (17). According to the EUROCAT classification omphaloceles and gastroschisis were included in this subgroup although it has been demonstrated that obesity is a risk factor for the development of omphaloceles but a protective fac- tor against gastroschisis. This might have influenced the above-mentioned non-significant results. However, the National Birth Defects Prevention Study was one of the studies that demonstrated the positive association of obesity and omphaloceles $(18,19)$. On the other hand, in the here presented study there was an association between a low BMI and an increased risk for the occurrence of gastroschisis. This is conform with the data published by Lam et al in 1999 who matched 104 cases of gastroschisis with controls and described an increased risk of 3 fold in underweighted women (20).

The number of cases with gastrointestinal tract anomalies was very small in this study, which might explain the observed association with obesity that was not described to this extend by other studies including more cases (1719). In contrast, the here presented association of maternal obesity with the development of multiple malformations in the fetus was also described by Watkins et al (19). Previously published matched case studies described that obese women had a higher risk of delivering children with neural tube defects which is in line with the here presented results. A recently published matched case control study investigating neural tube defects in 459 cases found that obese women had a significant OR of 2.45 of having children with this defect (21). Moreover, a published meta-analysis described not only an association with obesity but with maternal overweight, as well (12). In contrast, the occurrence of a fetal hydrocephalus had not been linked to maternal weight in several studies and the here presented data correlated with these results $(12,18,19)$. 
In 2012 Eckmann-Scholz et al published that in a cohort of women carrying fetuses with heart defects $54.3 \%$ had a BMI above $25 \mathrm{~kg} / \mathrm{m}^{2}$ leading to the assumption that obese women might be at increased risk (22). Our here presented data suggest a slight but not significantly increased risk for obese and overweighed women. In other studies that comprised a higher number of cases, a similar but significant association was described. Odds ratios published were between 1.15 and $2.0(12,18,19,23,24)$. With respect to conotruncal defects alone, we could show an increased risk in overweighed women of 1.7 fold and 1.9 fold in obese, but this was not statistically significant compared to previously published data (19). In a recently published meta-analysis, the increased risk of having children with conotruncal defects was shown to be significant in obese women highlighting the extended number of cases needed to reach significance (24). Gilboa et al investigated a cohort of 6440 children with congenital heart defects and demonstrated that especially muscular ventricle septum defects occurred in women who were underweighted (23). These findings could be confirmed in the smaller cohort presented above.

The published studies regarding the association of maternal BMI and the occurrence of urogenital anomalies are controversial. Whereas one study demonstrated a protective effect of increased maternal weight (19) another one described an increased risk of 1.7 fold for obese women (17). This increased risk could also be detected in our cohort, but the number of cases was not high enough to reach statistical significance.

The sensitivity of $94.9 \%$ for prenatal ultrasound diagnosis was relatively high in this study. Especially in underweighted and normal weighted women it reached 100\% and $95.5 \%$, respectively. In contrast, the sensitivity was lower in women with increased body weight (93.6\%), which highlights an association of maternal body weight with the detectability of fetal malformations. Similar results were published in a study that investigated the sensitivity of prenatal ultrasound between 18 and 24 weeks of gestation in 1098 cases (25). The authors described sensitivities of $97 \%$ in women with a normal BMI that decreased to $75 \%-88 \%$ among obese women. A Swedish study comprising basic ultrasound screenings performed on 19140 women could demonstrate that detection rates of fetal anomalies were $26 \%$ in the normal weight group, $29 \%$ in overweighed and only $19 \%$ in obese women. The better detection rate in the overweighed was explained by the fact that ultrasonographers took extra care to reach acceptable views, whereas this was technically impossible in the obese (26). Similar results were published by Maxwell et al (27). They describe that basic ultrasound screenings were more likely to be incomplete in obese women due to worse ultrasound conditions. In conclusion, the here presented data confirmed the published results that obese women are more likely to suffer from lower detection rates of fetal anomalies by ultrasound diagnostics.

In this study the association between maternal weight and fetal malformations could be confirmed. Although an association has been described in several articles, the underlying causes have yet to be discovered completely. The reason for the development of fetal anomalies is unknown in the majority of cases and often multifactorial. Obesity is one of the biggest risk factors for type 2 diabetes and gestational diabetes (28). It has been demonstrated previously in a rat model that a diabetic environment is disadvantageous for the embryonic development (29). A preexisting diabetes is associated with a 3-4 fold increased risk for the development of fetal anomalies and this is even higher if the diabetes is insufficiently treated $(30,31)$. The reason for this is supposed to be maternal hyperglycemia. The teratogenic effect of hyperglycemia has been demonstrated in several studies $(32,33)$. Even a slight increase in maternal blood sugar levels that does not yet account for gestational diabetes has been shown to have effects on the fetus (34). A recent study described that maternal glucose passes the placenta and leads to oxidative stress in the offspring resulting in a decreased expression of PAX-3. PAX-3 is of fundamental importance for the development of the neural tube. In its absence, p53 and other proapoptotic proteins lead to cell apoptosis and cause neural tube defects as well as dysmorphologies $(35,36)$. On the other hand, hyperinsulinism has also been linked independently to the development of fetal malformations. This occurs in obese and type 2 diabetic patients with peripheral insulin resistance (37). Prospective studies confirmed this suggesting that in obese women an undiagnosed diabetic condition most likely is the reason for the increased risk in developing fetal anomalies $(38,39)$. Furthermore, after supplementation with the same amount of folic acid obese women have a lower concentration in their serum compared to women with a normal BMI (40). This might explain why the risk reduction for neural tube defects was observed in normal weight women, only (41).

In conclusion, this retrospective matched case control study conducted in a single center was able to confirm the association between maternal BMI and the increased risk of fetal anomalies published by several groups. Moreover, the here presented data confirm that obese women not only suffer from an increased risk for fetal malformations. Also may but insufficient ultrasound conditions due to subcutaneous fat depots make it harder to detect and correctly diagnose fetal malformations. It is of paramount importance to refer these patients to specialist clinics with up to date equipment. Extra time for the exams in order to increase the sensitivity of antenatal screening in this patient cohort is necessary.

\section{Ethical Issues}

The study was conducted under the approval of the ethics committee of the medical faculty of the Christian-Albrechts University of Kiel (D478/14). Also, written informed consent was obtained from the patients for publication of this manuscript.

\section{Conflict of Interests}

None. 


\section{Financial Support}

None.

\section{Acknowledgments}

We would like to thank the patients for participating in this study as well as Juergen Hedderich supervising the statistical analyses.

\section{References}

1. James AH, Jamison MG, Brancazio LR, Myers ER. Venous thromboembolism during pregnancy and the postpartum period: incidence, risk factors, and mortality. Am J Obstet Gynecol. 2006;194:1311-5. doi:10.1016/j.ajog.2005.11.008.

2. Sebire NJ, Jolly M, Harris JP, et al. Maternal obesity and pregnancy outcome: a study of 287,213 pregnancies in London. Int J Obes Relat Metab Disord. 2001;25;1175-82. doi:10.1038/sj.ijo.0801670.

3. Weiss JL, Malone FD, Emig D, et al. Obesity, obstetric complications and cesarean delivery rate--a population-based screening study. Am J Obstet Gynecol. 2004;190:1091-7. doi:10.1016/j. ajog.2003.09.058.

4. Dinatale A, Ermito S, Fonti I, et al. Obesity and fetalmaternal outcomes. J Prenat Med. 2010;4:5-8.

5. Boots CE, Bernardi LA, Stephenson MD. Frequency of euploid miscarriage is increased in obese women with recurrent early pregnancy loss. Fertil Steril. 2014;102:455-9. doi:10.1016/j.fertnstert.2014.05.005.

6. Stamilio DM, Scifres CM. Extreme obesity and postcesarean maternal complications. Obstet Gynecol. 2014;124:227-32. doi:10.1097/ AOG.0000000000000384.

7. Meenakshi, Srivastava R, Sharma NR, Kushwaha KP, Aditya V. Obstetric behavior and pregnancy outcome in overweight and obese women: maternal and fetal complications and risks in relation to maternal overweight and obesity. J Obstet Gynaecol India. 2012;62:276-80. doi:10.1007/s13224-012-0215-z.

8. Heslehurst N, Simpson H, Ells LJ, et al. The impact of maternal BMI status on pregnancy outcomes with immediate short-term obstetric resource implications: a meta-analysis. Obes Rev. 2008;9:63583. doi:10.1111/j.1467-789X.2008.00511.x.

9. Usha Kiran TS, Hemmadi S, Bethel J, Evans J. Outcome of pregnancy in a woman with an increased body mass index. BJOG. 2005;112:768-72. doi:10.1111/ j.1471-0528.2004.00546.x.

10. Boney CM, Verma A, Tucker R, Vohr BR. Metabolic syndrome in childhood: association with birth weight, maternal obesity, and gestational diabetes mellitus. Pediatrics. 2005;115:e290-6. doi:10.1542/ peds.2004-1808.

11. Rasmussen SA, Chu SY, Kim SY, Schmid CH, Lau J. Maternal obesity and risk of neural tube defects: a metaanalysis. Am J Obstet Gynecol. 2008;198:611-9. doi:10.1016/j.ajog.2008.04.021.

12. Stothard KJ, Tennant PW, Bell R, Rankin J. Maternal overweight and obesity and the risk of congenital anomalies: a systematic review and meta-analysis. JAMA. 2009;301:636-50. doi:10.1001/jama.2009.113.

13. Heron M. Deaths: leading causes for 2010. Natl Vital Stat Rep. 2013;62:1-96.

14. Aagaard-Tillery KM, Flint Porter T, Malone FD, et al. Influence of maternal BMI on genetic sonography in the FaSTER trial. Prenat Diagn. 2010;30:14-22. doi:10.1002/pd.2399.

15. Best KE, Tennant PW, Bell R, Rankin J. Impact of maternal body mass index on the antenatal detection of congenital anomalies. BJOG. 2012;119:1503-11. doi:10.1111/j.1471-0528.2012.03462.x.

16. Dennedy MC, Avalos G, O’Reilly MW, O’Sullivan EP, Gaffney G, Dunne F. ATLANTIC-DIP: raised maternal body mass index (BMI) adversely affects maternal and fetal outcomes in glucose-tolerant women according to International Association of Diabetes and Pregnancy Study Groups (IADPSG) criteria. J Clin Endocrinol Metab. 2012;97:E608-12. doi:10.1210/jc.2011-2674.

17. Queisser-Luft A, Kieninger-Baum D, Menger $H$, Stolz G, Schlaefer K, Merz E. [Does maternal obesity increase the risk of fetal abnormalities? Analysis of 20,248 newborn infants of the Mainz Birth Register for detecting congenital abnormalities]. Ultraschall Med. 1998;19:40-4. doi:10.1055/s-2007-1000457.

18. Waller DK, Shaw GM, Rasmussen SA, et al. Prepregnancy obesity as a risk factor for structural birth defects. Arch Pediatr Adolesc Med. 2007;161:745-50. doi:10.1001/archpedi.161.8.745.

19. Watkins ML, Rasmussen SA, Honein MA, Botto LD, Moore CA. Maternal obesity and risk for birth defects. Pediatrics. 2003;111:1152-8.

20. Lam PK, Torfs CP, Brand RJ. A low pregnancy body mass index is a risk factor for an offspring with gastroschisis. Epidemiology. 1999;10:717-21.

21. Gao LJ, Wang ZP, Lu QB, Gong R, Sun XH, Zhao ZT. Maternal overweight and obesity and the risk of neural tube defects: a case-control study in China. Birth Defects Res A Clin Mol Teratol. 2013;97:161-5. doi:10.1002/bdra.23123.

22. Eckmann-Scholz C, Hoffmann U, Kramer HH, et al. Perinatal management of pregnancies with severe fetal heart defects and epigenetic aspects. J Matern Fetal Neonatal Med. 2012;25:2542-5. doi:10.3109/14 767058.2012.703725.

23. Gilboa SM, Correa A, Botto LD, et al. Association between prepregnancy body mass index and congenital heart defects. Am J Obstet Gynecol. 2010; 202:51e1- e10. doi:10.1016/j.ajog.2009.08.005.

24. Cai GJ, Sun XX, Zhang L, Hong Q. Association between maternal body mass index and congenital heart defects in offspring: a systematic review. Am J Obstet Gynecol. 2014;211:91-117. doi:10.1016/j. ajog.2014.03.028.

25. Dashe JS, McIntire DD, Twickler DM. Effect of maternal obesity on the ultrasound detection of 
anomalous fetuses. Obstet Gynecol. 2009;113:1001-7. doi:10.1097/AOG.0b013e3181a1d2f5.

26. Hildebrand E, Gottvall T, Blomberg M. Maternal obesity and detection rate of fetal structural anomalies. Fetal Diagn Ther. 2013;33:246-51. doi:10.1159/000343219.

27. Maxwell C, Dunn E, Tomlinson G, Glanc P. How does maternal obesity affect the routine fetal anatomic ultrasound? J Matern Fetal Neonatal Med. 2010;23:1187-92. doi:10.3109/14767050903551491.

28. Catalano PM. Obesity, insulin resistance, and pregnancy outcome. Reproduction. 2010;140:365-71. doi:10.1530/REP-10-0088.

29. Eriksson UJ, Lewis NJ, Freinkel N. Growth retardation during early organogenesis in embryos of experimentally diabetic rats. Diabetes. 1984;33:281-4.

30. Sheffield JS, Butler-Koster EL, Casey BM, McIntire DD, Leveno KJ. Maternal diabetes mellitus and infant malformations. Obstet Gynecol. 2002;100:925-30.

31. Hanson U, Persson B, Thunell S. Relationship between haemoglobin A1C in early type 1 (insulindependent) diabetic pregnancy and the occurrence of spontaneous abortion and fetal malformation in Sweden. Diabetologia. 1990;33:100-4.

32. Cockroft DL, PT Coppola. Teratogenic effects of excess glucose on head-fold rat embryos in culture. Teratology. 1977;16:141-6. doi: 10.1002/ tera.1420160205.

33. Freinkel N, Cockroft DL, Lewis NJ, Gorman L, S Akazawa, LS Phillips, et al. The 1986 McCollum award lecture. Fuel-mediated teratogenesis during early organogenesis: the effects of increased concentrations of glucose, ketones, or somatomedin inhibitor during rat embryo culture. Am J Clin Nutr. 1986;44:986-95.

34. HSCR Group, Metzger BE, Lowe LP, Dyer AR, Trimble ER, U Chaovarindr, et al. Hyperglycemia and adverse pregnancy outcomes. N Engl J Med. 2008;358:19912002. doi:10.1056/NEJMoa0707943.

35. Loeken MR. Current perspectives on the causes of neural tube defects resulting from diabetic pregnancy. Am J Med Genet C Semin Med Genet. 2005;135C: 77-87. doi:10.1002/ajmg.c.30056.

36. Yang P, Zhao Z, Reece EA. Activation of oxidative stress signaling that is implicated in apoptosis with a mouse model of diabetic embryopathy. Am J Obstet Gynecol. 2008;198:130e1-7. doi:10.1016/j. ajog.2007.06.070.

37. Hendricks KA, Nuno OM, Suarez L, Larsen R. Effects of hyperinsulinemia and obesity on risk of neural tube defects among Mexican Americans. Epidemiology. 2001;12:630-5.

38. Biggio JR Jr, Chapman V, Neely C, Cliver SP, Rouse DJ. Fetal anomalies in obese women: the contribution of diabetes. Obstet Gynecol. 2010;115:290-6. doi: 10.1097/AOG.0b013e3181c9b8c3

39. Moore LL, Singer MR, Bradlee ML, Rothman KJ, Milunsky A. A prospective study of the risk of congenital defects associated with maternal obesity and diabetes mellitus. Epidemiology. 2000;11:689-94.

40. Mojtabai R. Body mass index and serum folate in childbearing age women. Eur J Epidemiol. 2004;19: 1029-36.

41. Werler MM, Louik C, Shapiro S, Mitchell AA. Prepregnant weight in relation to risk of neural tube defects. JAMA. 1996;275:1089-92.

Copyright (c) 2016 The Author(s); This is an open-access article distributed under the terms of the Creative Commons Attribution License (http://creativecommons.org/licenses/by/4.0), which permits unrestricted use, distribution, and reproduction in any medium, provided the original work is properly cited. 